\title{
Chylomicron retention disease
}

INSERM

\section{Source}

INSERM. (1999). Orphanet: an online rare disease and orphan drug data base.

Chylomicron retention disease. ORPHA:71

Chylomicron retention disease (CRD) is a type of familial hypocholesterolemia characterized by malnutrition, failure to thrive, growth failure, vitamin E deficiency and hepatic, neurologic and ophthalmologic complications. 